\title{
Feature-Scale Analysis Using Ground-Penetrating Radar and Low Altitude Prospection at the Collins Mounds Site, Northwest Arkansas
}

Stephanie M. Sullivan

University of Arkansas

Tiago Attore

Human Environment Institute

Follow this and additional works at: https://scholarworks.sfasu.edu/ita

Part of the American Material Culture Commons, Archaeological Anthropology Commons, Environmental Studies Commons, Other American Studies Commons, Other Arts and Humanities Commons, Other History of Art, Architecture, and Archaeology Commons, and the United States History Commons

Tell us how this article helped you.

This Article is brought to you for free and open access by the Center for Regional Heritage Research at SFA ScholarWorks. It has been accepted for inclusion in Index of Texas Archaeology: Open Access Gray Literature from the Lone Star State by an authorized editor of SFA ScholarWorks. For more information, please contact cdsscholarworks@sfasu.edu. 


\section{Feature-Scale Analysis Using Ground-Penetrating Radar and Low Altitude}

Prospection at the Collins Mounds Site, Northwest Arkansas

\section{Creative Commons License}

\section{(c) (1) \&}

This work is licensed under a Creative Commons Attribution-NonCommercial 4.0 International License 


\title{
Feature-Scale Analysis Using Ground-Penetrating Radar and Low Altitude Prospection at the Collins Mounds Site, Northwest Arkansas
}

\author{
Stephanie M. Sullivan ${ }^{1}$ and Tiago Attore $^{2}$
}

${ }^{1}$ University of Arkansas

${ }^{2}$ Human Environment Institute

Geophysical survey and other non-invasive methods are, in some cases, the only options available for archaeological investigation. This is exemplified at the Collins site, a possible Late Woodland to Middle Mississippian period, multi-mound, civic ceremonial center in Northwest Arkansas. The site is located on private property and although excavation is not allowed, non-invasive survey methods are permitted on its northern section. This paper presents the results of a ground-penetrating radar survey over Mounds $B, C$, and $D$. The results reveal a number of features that are interpreted as mortuary structures as well as evidence of multiple building episodes over time within distinct layers of Mound C. A high-resolution DEM generated with aerial imagery is used in interpreting the GPR data as well as to provide an updated map of mound size and distribution. By integrating the GPR data with the DEM, orthoimagery, and magnetic gradiometry data from a previously documented survey, and comparing the results to ethnohistoric accounts, interpretation of the geophysical data is enhanced. Geophysical survey is often used to assess an archaeological site on a landscape scale. By narrowing the scope to individual mounds, this article demonstrates how multiple, complementary technologies, when used in concert, can inform on the feature level.

\section{Background}

The Collins mound complex (3WA1) is one of three multi-mound civic-ceremonial centers in northwestern Arkansas. The site is nestled within the western Ozark Highlands, a physiographic region spanning across northwestern Arkansas, southwestern Missouri, and northeastern Oklahoma, placing it within the northern cultural boundary of the Caddo Area (Perttula 1992:136143). Five earthen mounds are distributed across the site with a tier of three in the north and two in the south (Figure 1). The property is divided by a barbed wire fence extending east-west across the site with each section owned separately by a private landowner. Survey of any kind is prohibited south of the fence due to the wishes of that section's landowner. Access to the northern section has been granted, but with restriction. Non-invasive survey methods are permitted, however excavation is not allowed.

Systematic survey is needed to work out the developmental sequence of the site as well as to understand its use history and role within the archaeological framework of the region. Because excavation is not allowed, the Collins site is a perfect candidate for "inquiry-based archaeogeophysics" (Thompson and Pluckhahn 2010:38). In this context, rather than using geophysical survey as a post hoc method, it is used as a principle source of data. The survey must be situated within a theoretical framework driven by specific research questions allowing anthropological interpretations to be derived from the results (see Thompson et al. 2011).

This need was first addressed through a magnetic gradiometry survey conducted by Sullivan and McKinnon (2013), which revealed numerous architectural features, some of which are interpreted as mortuary structures (Figure 2). The excellent magnetometry results prompted further non-invasive investigations. Although it was not particularly fruitful, a thermal imaging and near-infrared survey was performed over the northeastern section of the site to test an experimental thermal data processing technique in an effort to detect archaeological features by reducing vegetation noise (Cool 2015:66-77). Additionally, aerial images were collected over the northwestern section of the site to produce a high-resolution digital elevation model (DEM) including elevations for Mound D (Sullivan et al. 2015).

This article presents the results of an aerial imaging survey over the site's northeastern section as well as the results of ground-penetrating radar (GPR) survey over Mounds B, C, and D. The GPR survey 

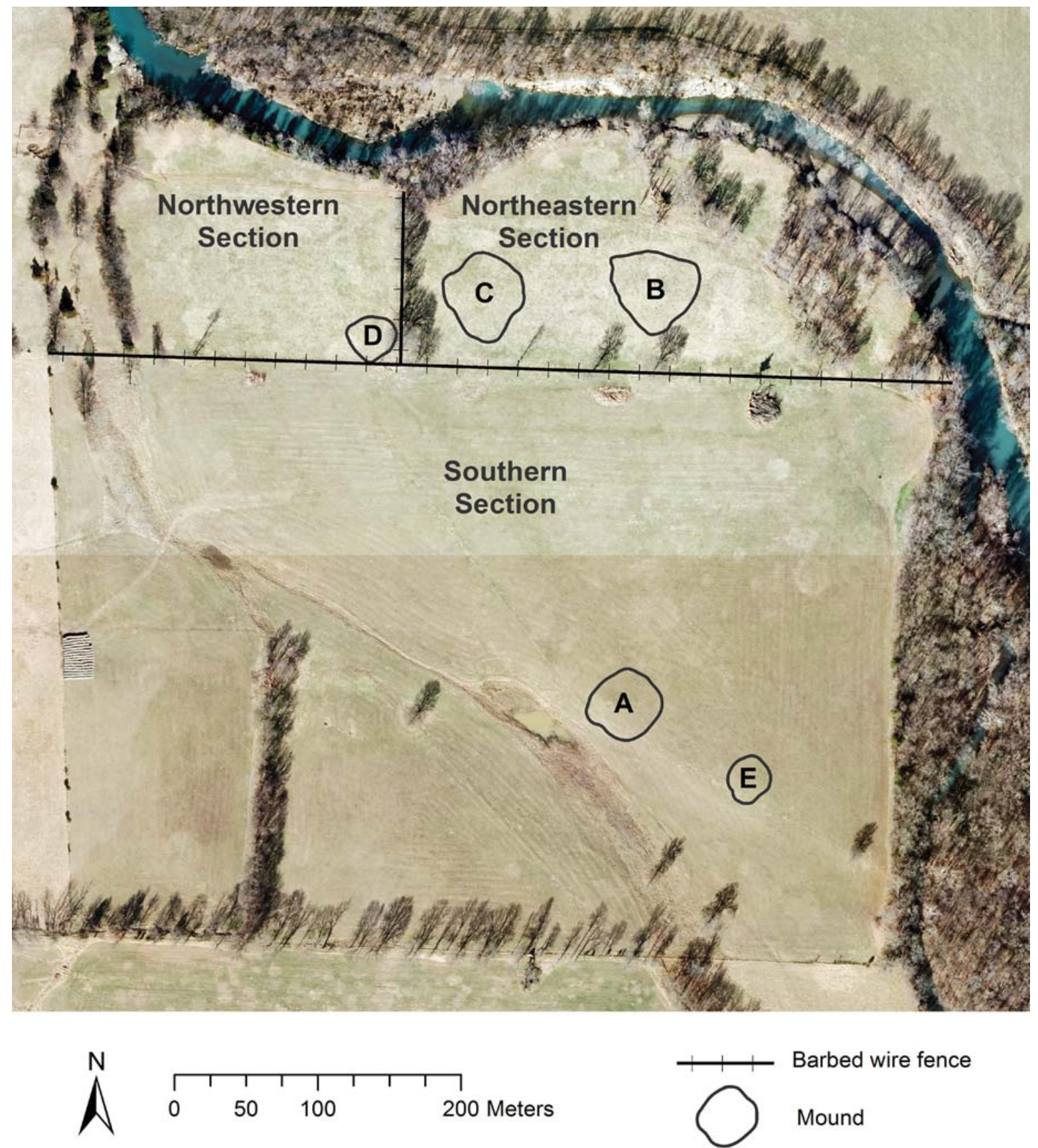

Figure 1. Map of the Collins site including mound layout and sections of the site as they are referred to in the text.

offers a complimentary dataset with which to compare the previously acquired magnetic gradiometry data (see Figure 2) (Clay 2001). Interpretation of the GPR data is bolstered through its integration with the magnetic gradiometry and aerial imaging datasets in a geographic information system (GIS) (see Gaffney 2008; Kvamme 2006; Neubauer 2004).

\section{Aerial Survey}

Methods

A high-resolution DEM was needed to accurately map the size and orientation of the mounds, to obtain elevation data across the site, and to attempt to topographically correct the GPR data presented later 


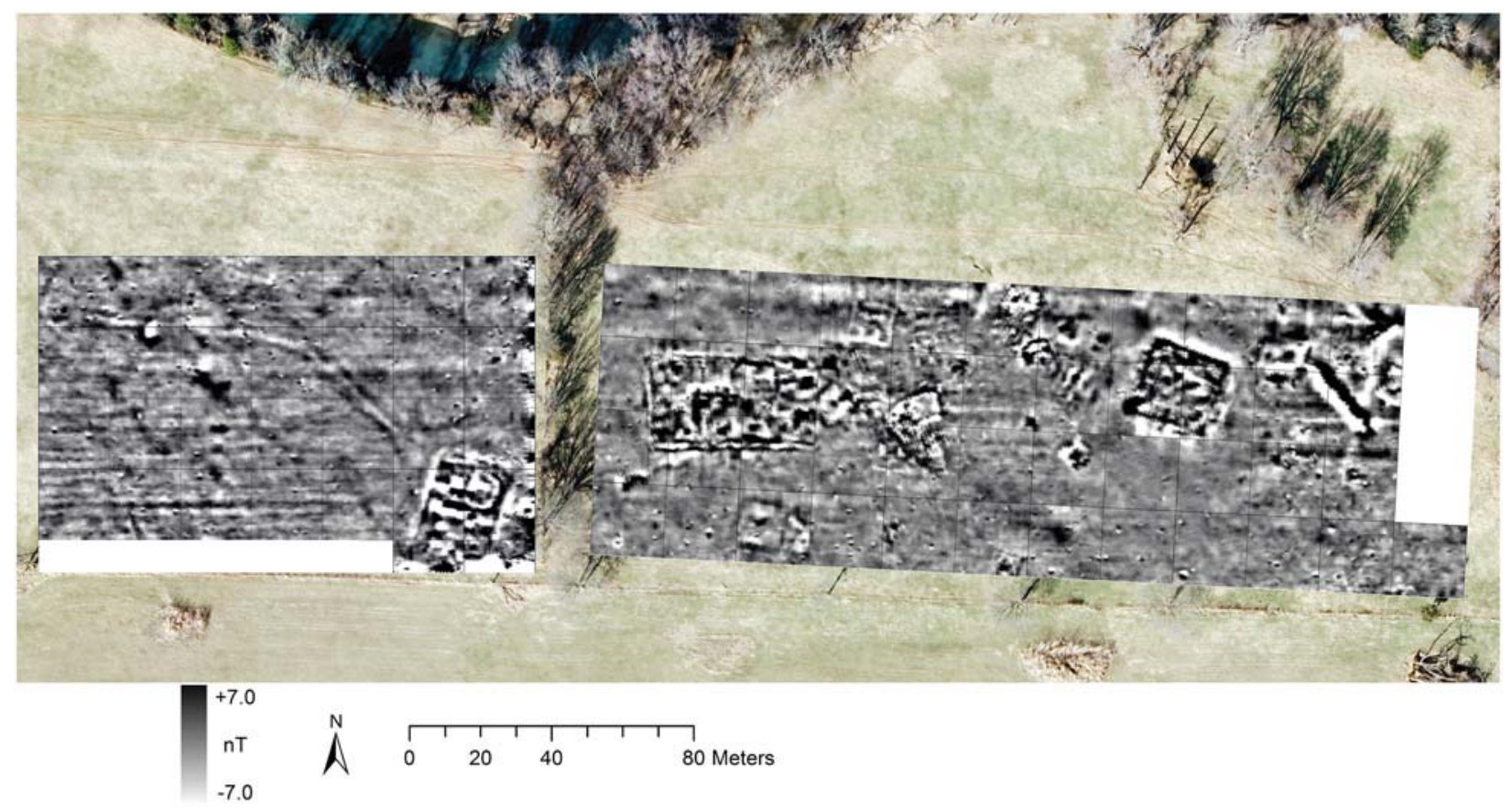

Figure 2. Results of magnetic gradiometry survey (after Sullivan and McKinnon 2013:75).

in this article. To accomplish this, aerially acquired imagery was processed in photogrammetric software. Color imagery was obtained over the northeastern section of the site using a Nikon D600 DSLR camera with 24.3 megapixels and a $35.9 \times 24.0 \mathrm{~mm}$ sensor. The camera was fixed on a Cinestar 8 unmanned aerial vehicle (UAV) by way of a gimbal, which allowed the camera to maintain a fixed position by pivoting independently of the pitching and rolling of the UAV.

The camera's intervalometer was set to take one picture per second. In conjunction with the rate of image collection, the height, speed, and transect spacing of a predetermined GPS-guided flightpath ensured sufficient overlap of the images needed for alignment in postprocessing.

Twelve ground control points (GCPs) were evenly distributed across the survey area to both aid in image alignment and to allow for georeferencing. The locations of the GCPs were mapped using a real-time kinematic (RTK) global navigation satellite system (GNSS) survey. Two Leica GS15 receivers and a CS15 controller were employed in the survey with one receiver acting as a base station and the other as a rover. During RTK survey, the rover quickly and accurately measures its position in relation to the base station by receiving a correction signal from the base.
Measurements recorded by the rover at the Collins site yielded a horizontal accuracy of $2 \mathrm{~cm}$ after postprocessing.

Agisoft PhotoScan software was used to process the images into a single, georectified orthophoto. A DEM was then generated and exported as a GeoTiff for use in a GIS. Figure 3 shows the resulting DEM for the northeastern section in addition to the DEM from the northwestern section presented in Sullivan et al. (2015:129).

\section{DEM Derived Products}

The newly acquired DEMs allowed for the production of an updated site map. The updated map, displaying the most current size and position of each of the mounds, is shown in Figure 1. The georectified, high-resolution DEMs were imported into ArcMap and draped over orthoimagery downloaded from USGS The National Map. A contour layer with a contour interval of $0.25 \mathrm{~m}$ was generated based on the DEMs. The boundaries of Mounds B, C, and D were digitized using the contour layer and then converted to shapefiles. The extent of each mound boundary is located at $395.5 \mathrm{~m} \mathrm{HAE}$ (height above ellipsoid). This boundary was chosen based on visual analysis of the DEM as well as from the ground. 


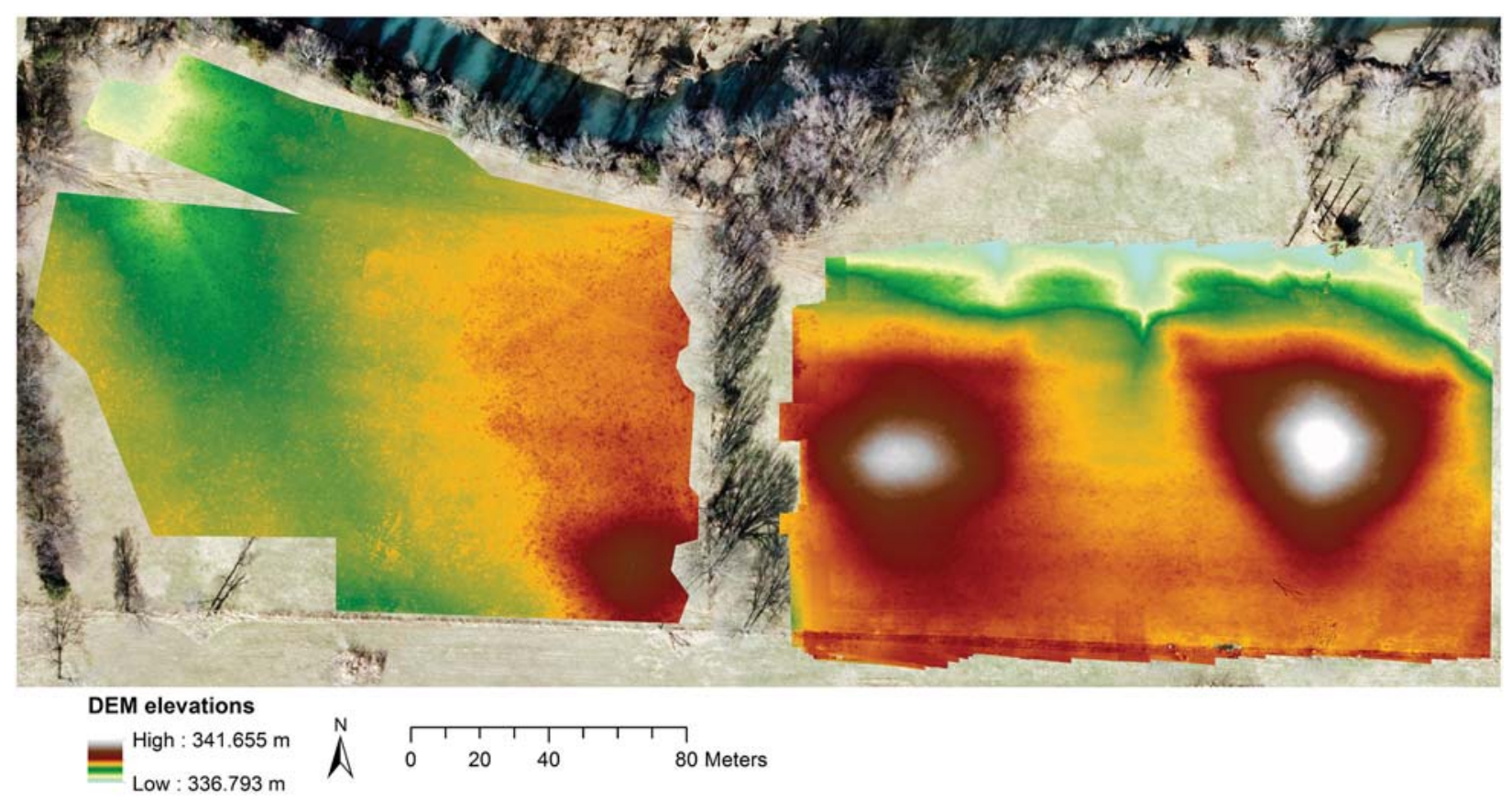

Figure 3. DEM of the survey area across the northern portion of the Collins site.

In the 1980s, Kay et al. (1989:136) mapped the size and orientation of the five mounds. Since access to the southern section of the site - by land or by air - is currently prohibited, it was not possible to resurvey Mounds A and E for the purpose of mapping. The southern mounds were placed on the map in Figure 1 by rubbersheeting the Kay et al. map to the base orthoimagery. This method worked well as the barbed wire fences in the map could be matched to the fences on the imagery. Although the fence extending diagonally through the southern section of the map is no longer present, soil marks left on the surface are easily visible in the imagery. After rubbersheeting the map, Mounds $A$ and $E$ were digitized and converted to shapefiles. Measurements of mound dimension were made as a final check of the accuracy of the rubbersheeting. Kay et al. (1989:137) gives a diameter of $51 \mathrm{~m}$ for Mound A, which matches the diameter of the Mound A shapefile. Specific measurements for the five mounds have not been given in previous publications. The GIS generated map layers make for easy measuring of mound parameters. Measurements for each of the mounds including area, diameter, and height are given in Table 1 .

\section{Ground-penetrating Radar Survey}

Based on reports from excavations at other multi-mound archaeological sites in the region (Bell 1972; Kay et al. 1989; Kay and Sabo 2006), it is suspected that one or more of the mound structures visible in the magnetic gradiometry data from Collins is a charnel house similar to that found at the Harlan site on the westernmost

\begin{tabular}{ccccccc}
\hline \hline Mound & $\begin{array}{c}\text { Max Elevation } \\
\text { (HAE) }\end{array}$ & $\begin{array}{c}\text { Height } \\
(\mathbf{m})\end{array}$ & $\begin{array}{c}\text { Perimeter } \\
(\mathbf{m})\end{array}$ & $\begin{array}{c}\text { Area } \\
(\mathbf{m} 2)\end{array}$ & $\begin{array}{c}\text { Diameter N-S } \\
(\mathbf{m})\end{array}$ & $\begin{array}{c}\text { Diameter E-W } \\
(\mathbf{m})\end{array}$ \\
\hline $\mathbf{A}$ & N/A & $\sim 3.00$ & 156 & 1837 & 50 & 51 \\
$\mathbf{B}$ & 341.66 & 2.16 & 191 & 2550 & 58 & 57 \\
$\mathbf{C}$ & 340.90 & 1.40 & 183 & 2430 & 62 & 56 \\
$\mathbf{D}$ & 340.25 & 0.75 & 102 & 783 & 32 & 33 \\
$\mathbf{E}$ & N/A & $\sim 1.00$ & 98 & 726 & 33 & 30 \\
\hline \hline
\end{tabular}

Table 1. Mound measurements at the Collins site (elevation given in meters above the WGS84 ellipsoid; perimeter, area, and diameter given in planar measurements). 
border of the Ozark Highlands in northeast Oklahoma (Sullivan and McKinnon 2013). Harlan-style charnel houses exhibit two primary characteristics that should, in theory, be identifiable in geophysical data. First, charnel houses were burned to the ground in accordance with a ritual cycle. This characteristic is identified in the high magnetic gradiometry values for the structural footprints associated with the Collins mounds, which suggests that the structures were burned. Second, after the ritual destruction of a Harlan-style charnel house, the remains were capped over with soil and a new structure built over the same location. Magnetic gradiometry returns a two-dimensional view of variations in the magnetic field of the near-subsurface making it difficult to determine feature depth. Therefore, groundpenetrating radar, which facilitates three-dimensional imaging of the subsurface, was used over Mounds B, C, and $\mathrm{D}$ to determine if multiple building episodes could be distinguished within distinct layers of the mounds.

\section{Methods}

The survey employed a Geophysical Survey System, Inc. SIR 3000 single-channel ground-penetrating radar system outfitted with a shielded $400 \mathrm{MHz}$ antenna to acquire data over the three mounds in the northern portion of the site. Ground-penetrating radar is an active method in which an antenna transmits radio waves into the ground and then measures the time it takes for the energy to be sent back to the surface (Conyers 2013). When the radio waves encounter a material with a relative dielectric permittivity (RDP) that is different from the surrounding soil matrix, the waves are reflected back to the surface at a different rate. Once the RDP is known, the two way travel time of the signal can be converted to distance allowing the depth of subsurface features to be calculated. Variations in the amplitude of the returned signals are recorded along a two-dimensional, vertical, reflection profile. A single reflection profile may be used for analysis of the subsurface; or multiple, closely spaced profiles may be collected within the survey area. Multiple reflection profiles can then be aligned in processing software to produce a three-dimensional dataset which may be horizontally "sliced" revealing features across the survey area at various depths.
The magnetic gradiometry data collected by Sullivan and McKinnon (2013) guided the placement of the GPR survey grids. Profiles in each survey grid were collected unidirectionally from the south to the north along transects spaced at $0.5 \mathrm{~m}$ intervals. Collecting data in the same direction along each transect reduces reflection errors in the data by maintaining the antenna orientation with respect to the ground (Conyers 2013). Each profile extends the length of the entire survey grid (rather than breaking up the grid into $20 \times 20 \mathrm{~m}$ segments as is done with other geophysical methods) to reduce trace misalignment and edge discontinuities (see Ernenwein and Kvamme 2008). The location of the GPR grids was measured in real world coordinates with an RTK GNSS survey using the same methodology as described above for the aerial survey. After postprocessing, the measurements recorded by the rover yielded a horizontal accuracy of $2 \mathrm{~cm}$.

During processing of the GPR data, time zero correction was set on each profile to obtain a more accurate estimated depth. Hilbert transform was applied to evaluate the trace envelope enabling a more representative form of the reflected events to be produced (Jol 2008) as well as allowing the data to be thinly sliced (Goodman and Piro 2013). RDP was estimated through hyperbola fitting to convert two way travel time to depth (migration was not performed in order to keep all acquired data within the dataset). Next, the profiles were sorted into a grid and the z-plane was gridded using the inverse distance to a power algorithm through an isotropic search radius based on the trace envelope extracted by the magnitude data after the Hilbert transform. In this manner, three-dimensional data for each mound were generated into several slices along the z-axis. The surface terrain was then taken into account by using the DEMs in an attempt to topographically correct the reflection profiles.

Two forms of topographic correction were attempted when making the slices. The first method preserved an absolute depiction of depth, but negatively affected the parameters needed for interpolation, rendering the slices useless. The second method warped the amplitude slices against the modeled surface. This method yielded much more useful images, but caused different depths to be displayed simultaneously. Visualizing the data in this way is analogous to the 


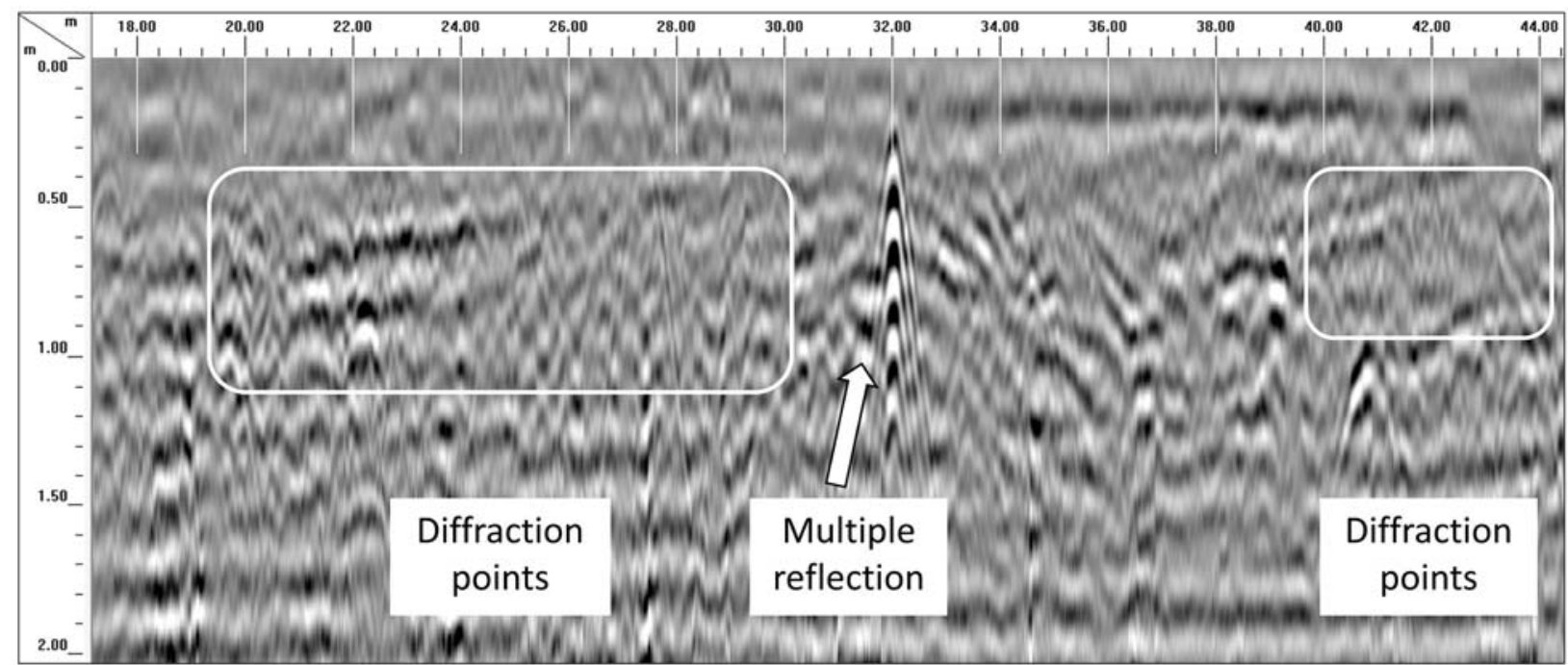

Figure 4. Section of Profile 66 (after time zero correction and background removal) over Mound B displaying many diffraction points and one multiple reflection over meter 32.

slices having an azimuthal projection as the slices are "flat" rather than portraying a curved surface. Therefore, although a true topographic correction could not be made with the available data, the "pseudo" correction was useful for visually interpreting the processed GPR results. Each amplitude slice presented below contains a layer of data between 2 and $4 \mathrm{~cm}$ thick, allowing the features present in the data to be easily visible providing a wider context of the data. Note that in the slices, locations of high amplitude are represented as white and areas of low amplitude are displayed as black.

Before discussing the results of the processed data, two striking features should be mentioned regarding the GPR profiles acquired over all three of the mounds. First, the high number of diffraction points, or points where there is bending of the radar wave, throughout the profiles makes it difficult to differentiate distinct layers in the data. Second, multiple reflections (MRs) can be seen within many of the profiles (Figure 4).

Multiple reflections occur when radar waves encounter a highly reflective material causing the energy to reflect off of the material, travel back to the ground surface to be reflected again from the ground-air interface, back to the reflective material, and then back again to the surface (Conyers 2013:57). Although we are not certain of the cause of the MRs in the Collins profiles, one potential explanation is the presence of post molds. Post molds are likely composed of a soil matrix with less cohesion than that of the soil matrix surrounding them causing the post molds to retain a larger quantity of water or air. The increased quantity of water or air trapped in these locations could generate multiple reflections patterns in the profiles. Burrows or pit features may also cause the same phenomenon. We have plotted the multiple reflections on each amplitude slice in an attempt to correlate them with the features seen in the slices. All MRs are represented in the same way, as points; and all are plotted over each slice - regardless of their size and depth - as the interpolation algorithm used during processing causes them to fade away, rendering the placement of the depth for each difficult.

The processed and sliced GPR data were imported into a GIS using the grid coordinates acquired through the GNSS survey to position the data over the base orthoimagery. Figure 5 shows the orientation of each GPR grid. In the figure, the grids are draped over the magnetic gradiometry data layer displayed at 40 percent translucence. Mound boundaries are shown in white to show the positioning of the data in relation to the mounds.

\section{Mound B Results}

The Mound B GPR grid is composed of 121 profiles collected along the $y$-axis over a survey area of $60 \mathrm{x}$ $60 \mathrm{~m}$. Slices were generated in $4 \mathrm{~cm}$ increments along 


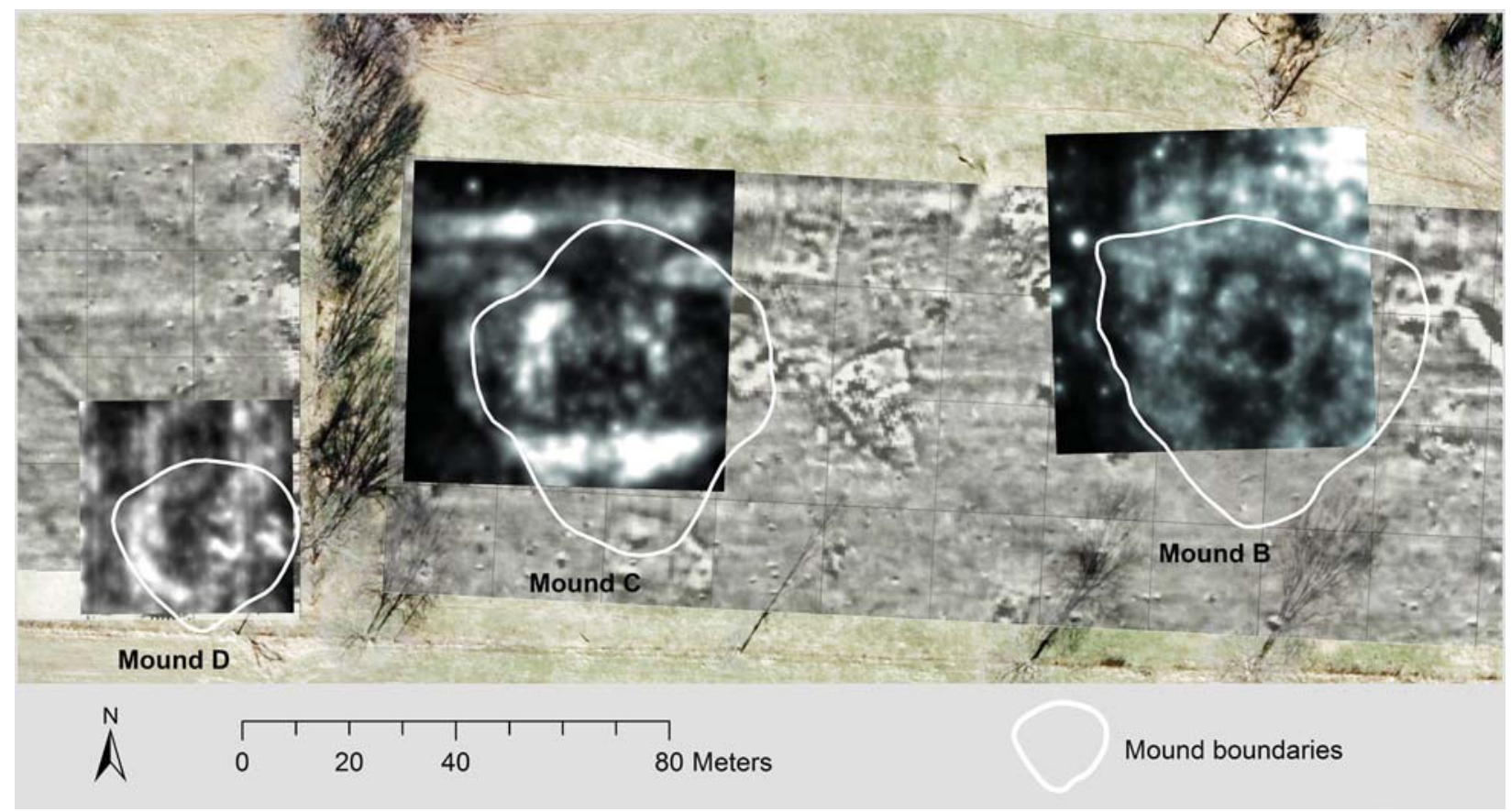

Figure 5. Location of the GPR survey grids in relation to the magnetic gradiometry data and orientation of the mounds.
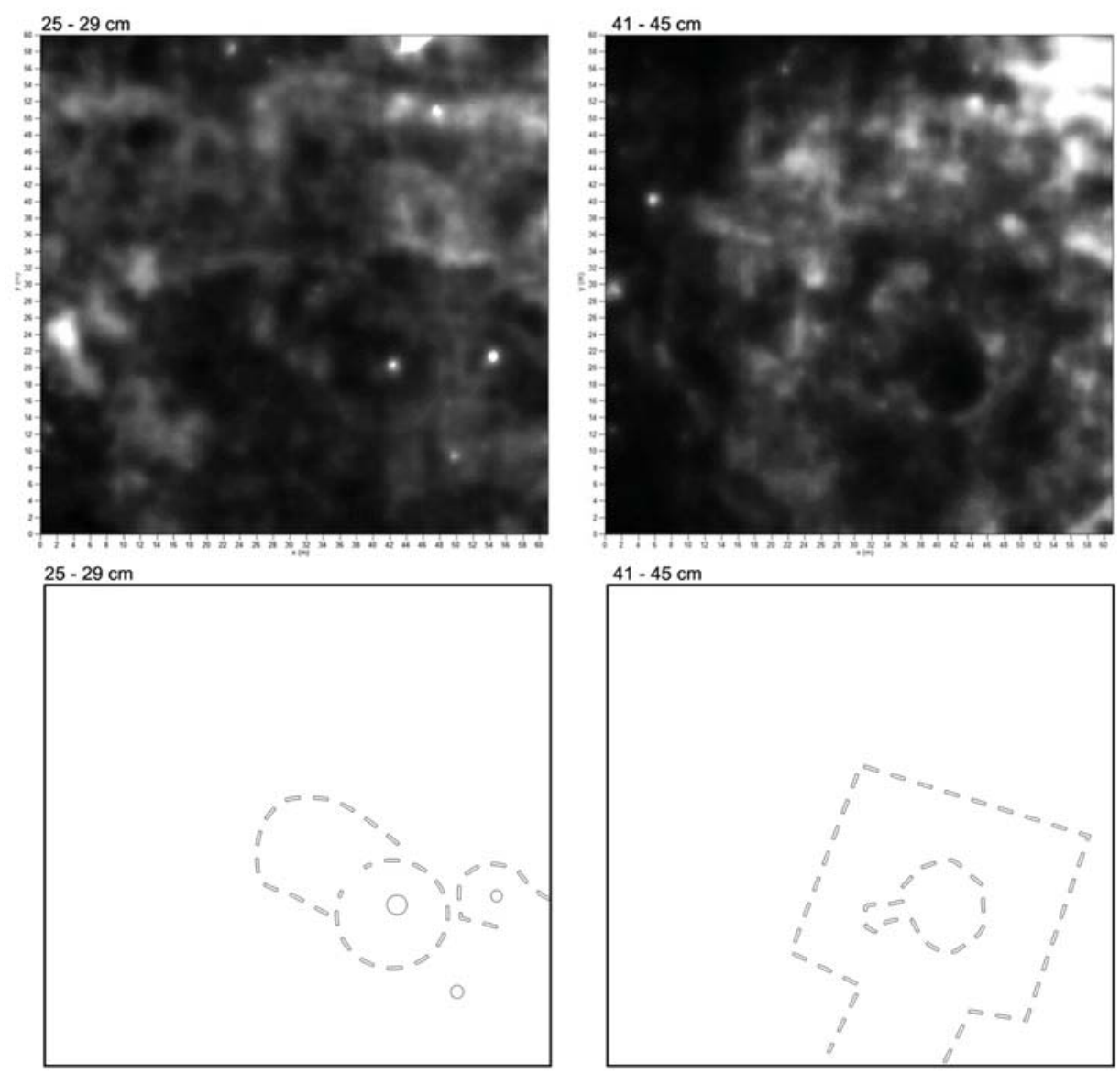

Figure 6. Amplitude slices at different depths over Mound B (top). Features drawn over the slices at the given depths on Mound B (bottom). 

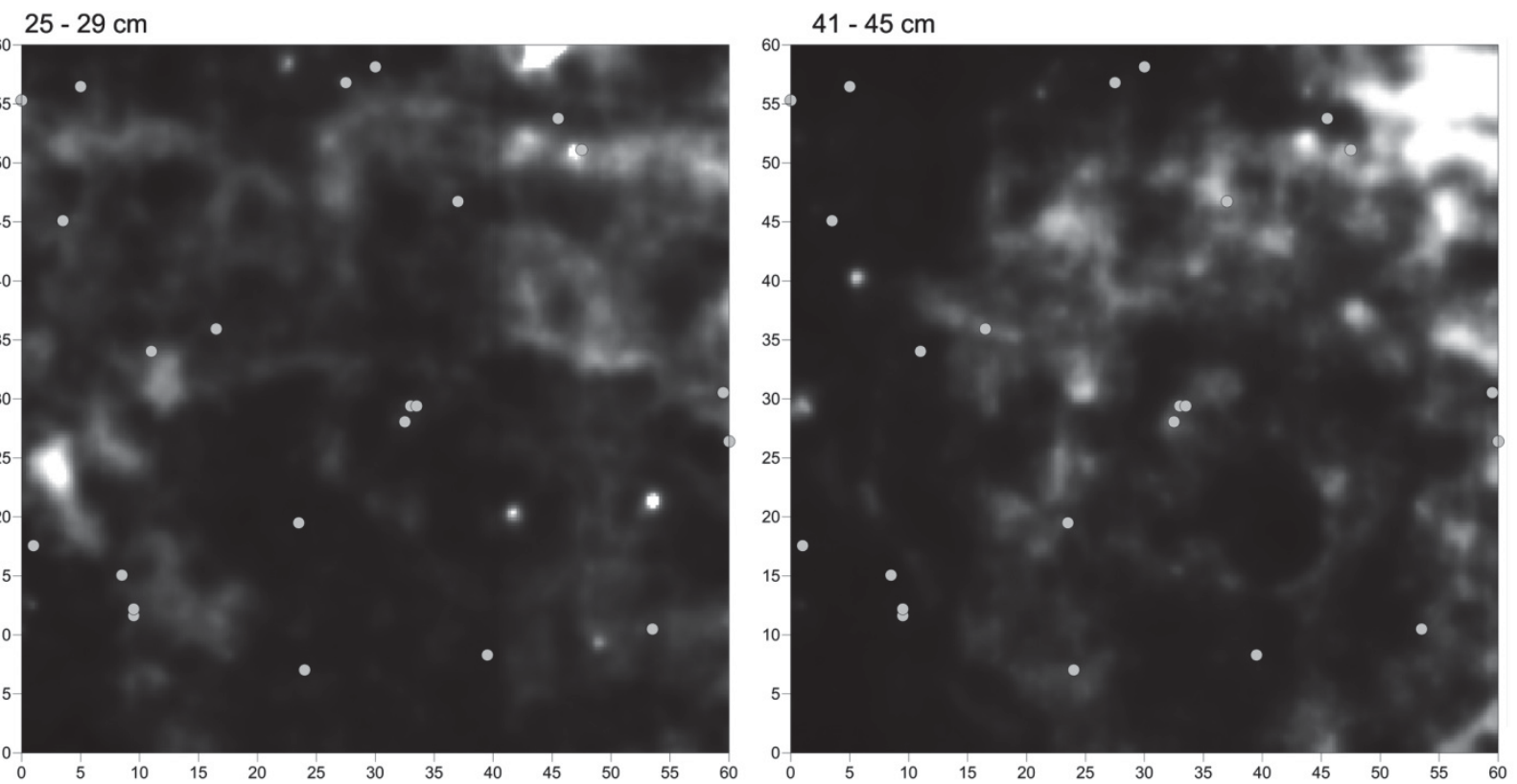

Figure 7. Multiple reflections plotted over the Mound B amplitude slices.

the z-axis. Two slices depict what appear to be two different archaeological contexts or layers in the data (Figure 6).

The first layer, between 25 and $29 \mathrm{~cm}$ in depth, shows a circular feature flanked by two other features. The circular feature is positioned perfectly in line with the apex of the mound. It appears interrupted in its northwest face from which it annexes to a contiguous feature. Three features appearing as white dots in the data are visible in the southeast quarter of the grid. The second layer, ranging from 41 to $45 \mathrm{~cm}$, also exhibits a circular feature centered with the apex of the mound. It is roughly $10 \mathrm{~m}$ in diameter and articulates to a small annex to the west. The circular feature appears within a distinctly square feature, which measures approximately $20 \mathrm{~m}$ per side. The square feature opens to the southwest with two linear parallel features, each approximately $7 \mathrm{~m}$ long, extending to the southwest (see Figure 6). The context of this deeper layer appears down to $60 \mathrm{~cm}$ in depth, after which the data turns to static.

Multiple reflections were plotted over the slices to determine whether they correlate with the features described above. A small cluster of three MRs at the center of the surveyed area seem to be related to the annex of the circle like feature in the first layer. Some of the MRs appear to be related to the square feature, while several MRs occur off-mound (Figure 7).

\section{Mound C Results}

The Mound C GPR grid is composed of 121 profiles collected along the $y$-axis over a survey area of $60 \mathrm{x}$ $60 \mathrm{~m}$. Slices were generated in $2 \mathrm{~cm}$ increments along the $\mathrm{z}$-axis. Mound $\mathrm{C}$ contains the richest data of the three mounds surveyed. Four layers appears to contain different contexts within the mound (Figure 8 ). The first slice, ranging from 48 to $50 \mathrm{~cm}$, depicts a large rectangular feature, the eastern boundary of which likely lies just beyond the survey area. The middle of the north and south faces of the feature seem to be interrupted.

At $74-76 \mathrm{~cm}$ (see Figure 8), there is a smaller rectangular feature also exhibiting interruptions in its north and south faces. A series of high amplitude events are present within the feature and continue with depth as seen in the slice taken between 83 and $85 \mathrm{~cm}$. This deeper layer does not portray the right angled feature corners visible in the more shallow contexts.

The final layer, between 101 and $103 \mathrm{~cm}$ in depth, displays a small, high amplitude, "U" shaped feature in the middle of the survey area (see Figure 8). This feature was only spotted after plotting the multiple reflections (Figure 9) as the MRs seems to be closely related to this feature. In addition, just to the east of the "U" shaped feature, a feature comprised of low amplitude areas and somewhat resembling an " $X$ " shape 

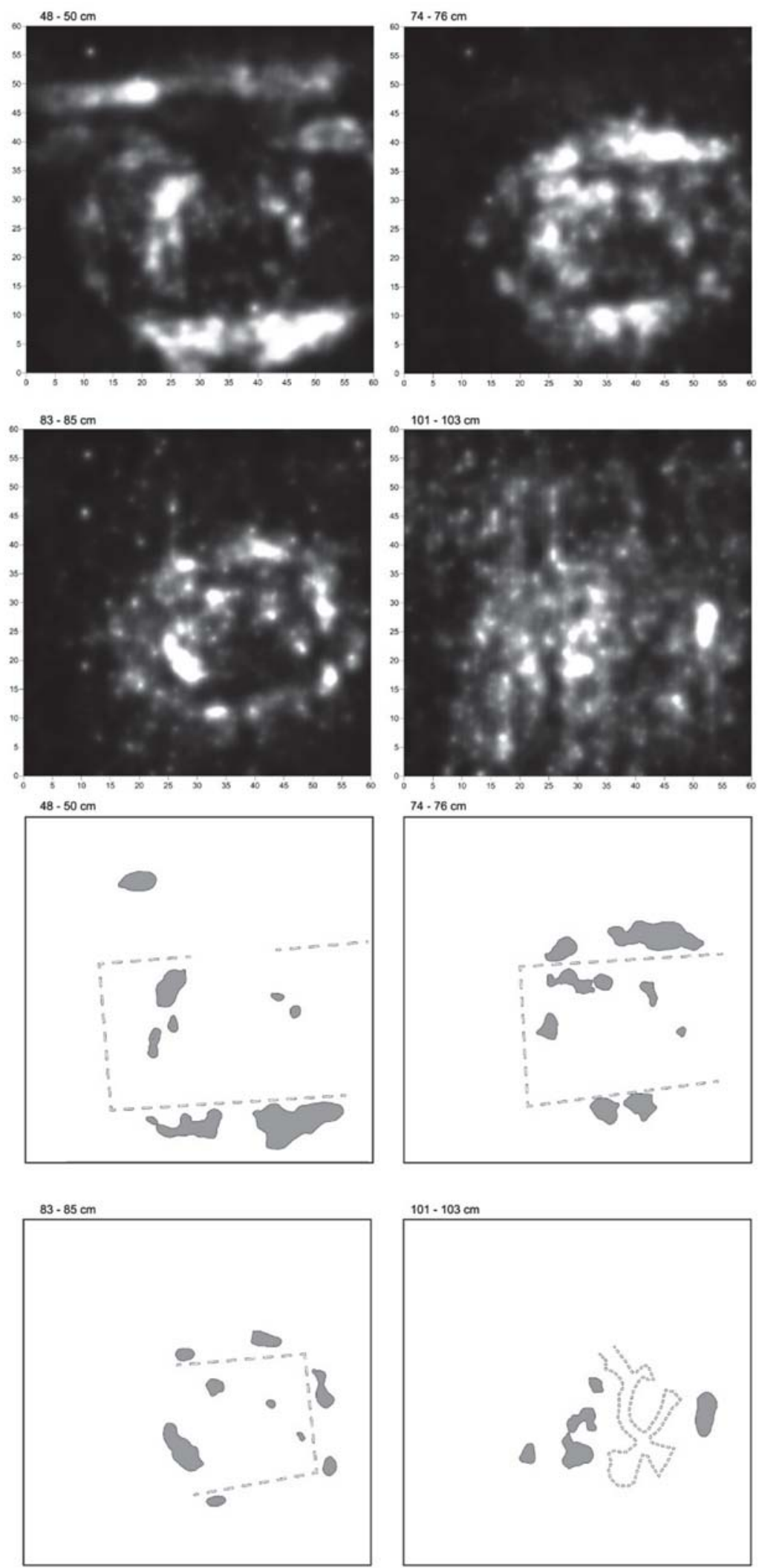

Figure 8. Amplitude slices at different depths over Mound C (top two rows). Features drawn over the slices at the given depths on Mound C (bottom two rows). 

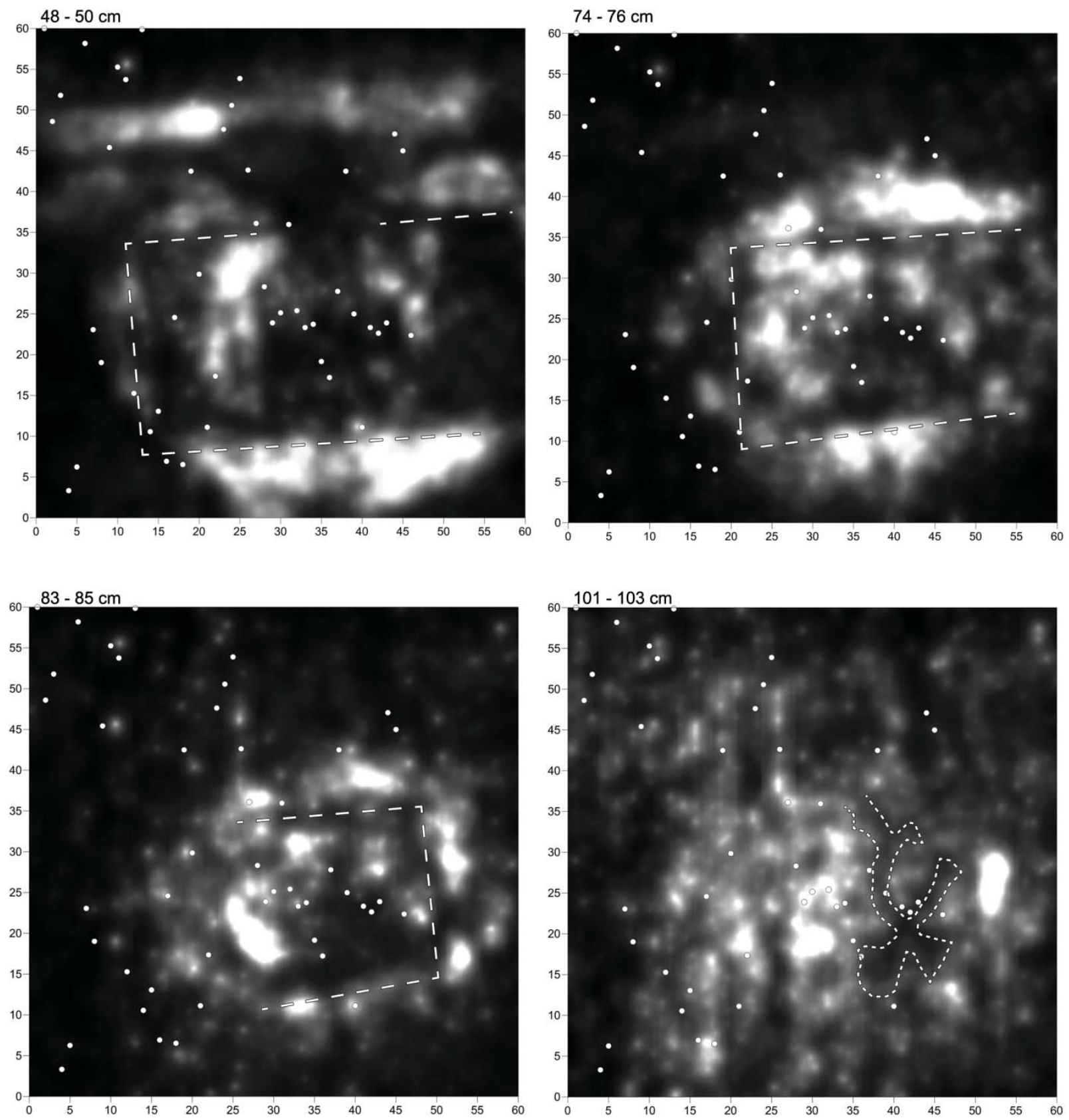

Figure 9. Multiple reflections and features plotted over the Mound C amplitude slices.

is present (see Figure 8). This feature also seems to be related to a series of the MRs (see Figure 9).

\section{Mound D Results}

The Mound D GPR grid is composed of 81 profiles collected along the $y$-axis over a survey area of $40 \mathrm{x}$ $40 \mathrm{~m}$. Slices were generated in $3 \mathrm{~cm}$ increments along the z-axis. This mound yielded the simplest data of the three mounds surveyed with only one layer presenting an interesting archaeological context.

Between 87 and $90 \mathrm{~cm}$ in depth, a half circle is formed by areas of high amplitude to the west and south, while a smaller area of high amplitude appears directly to the east (Figure 10). Between them, an area of low amplitude forms another " $\mathrm{X}$ " like feature resembling the one found in the deepest context of Mound C, although the feature is not as clearly rendered in the Mound D 
$87-90 \mathrm{~cm}$

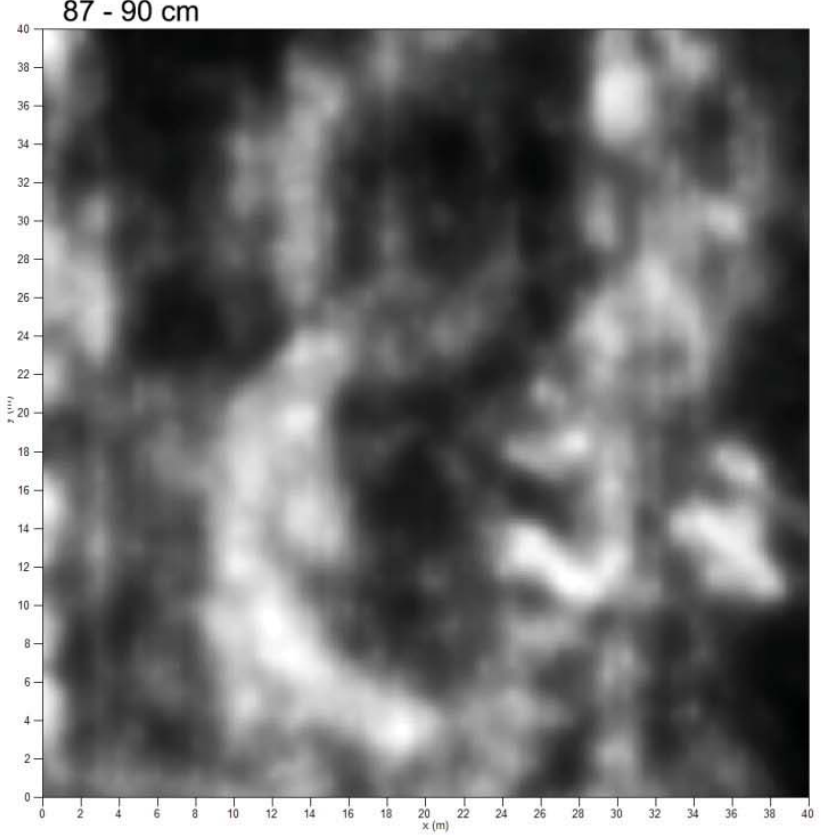

$87-90 \mathrm{~cm}$

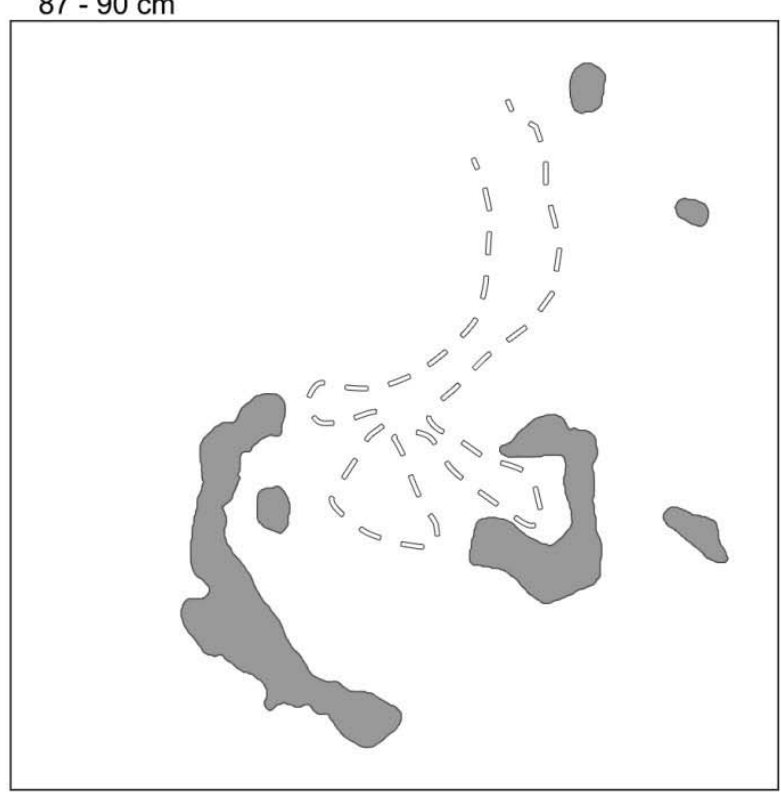

Figure 10. Amplitude slice from Mound D (left). Features drawn over the slice at the given depth (right).

data. A series of the MRs also appear to be closely related to the feature (Figure 11).

\section{Discussion}

A number of studies addressing architectural variation among Caddo archaeological sites identify the use of "specialized" buildings (Harrington 1920; Kay and Sabo 2006; Perttula 2009; Perttula and Rogers 2007; Rogers 1982; Schultz 2010; Spock 1977; Trubitt 2010; Walker 2009; Webb 1940). Specialized buildings are recognized by attributes such as extended entranceways, partitions, being unusually sized or shaped, and being associated with mounds. The structures associated with the mounds at the Collins site possess most of these characteristics and there is little question that they fall into the category of specialized buildings. However, understanding how the structures at the Collins site were used is less clear. In an attempt to understand the structural features in the Collins data, interpretation was facilitated by integrating the GPR data with the DEMs, the newly produced mound boundaries, the magnetic gradiometry data, and the orthoimagery in a GIS.
Mound B

Two different contexts seem to be evident in the amplitude slices from Mound B. However, teasing out distinct layers in the data, which might represent multiple construction episodes, is difficult as there does not appear to be thick layers of fill between potential episodes of construction. This makes it difficult to identify distinct layers within the profiles. Therefore, it is unknown if the features visible in each of the amplitude slices are concomitant (see Figure 6).

Starting with the deepest context of the Mound B GPR data, shown in the slice from $41-45 \mathrm{~cm}$, a square structure is immediately apparent. A large extended entryway articulates the structure to the southwest. A circular feature of low amplitude centered within the structure likely represents a prepared floor. One of the MRs plotted in Figure 7 is positioned in the southwest corner of the structure, potentially representing a corner post.

In the shallowest context of the Mound B GPR data, three white circles representing areas of high amplitude in the southeast quarter of the slice are interpreted to be post molds. The prepared floor from the previous layer continues into this shallower context. One of the post molds is centered within the prepared 


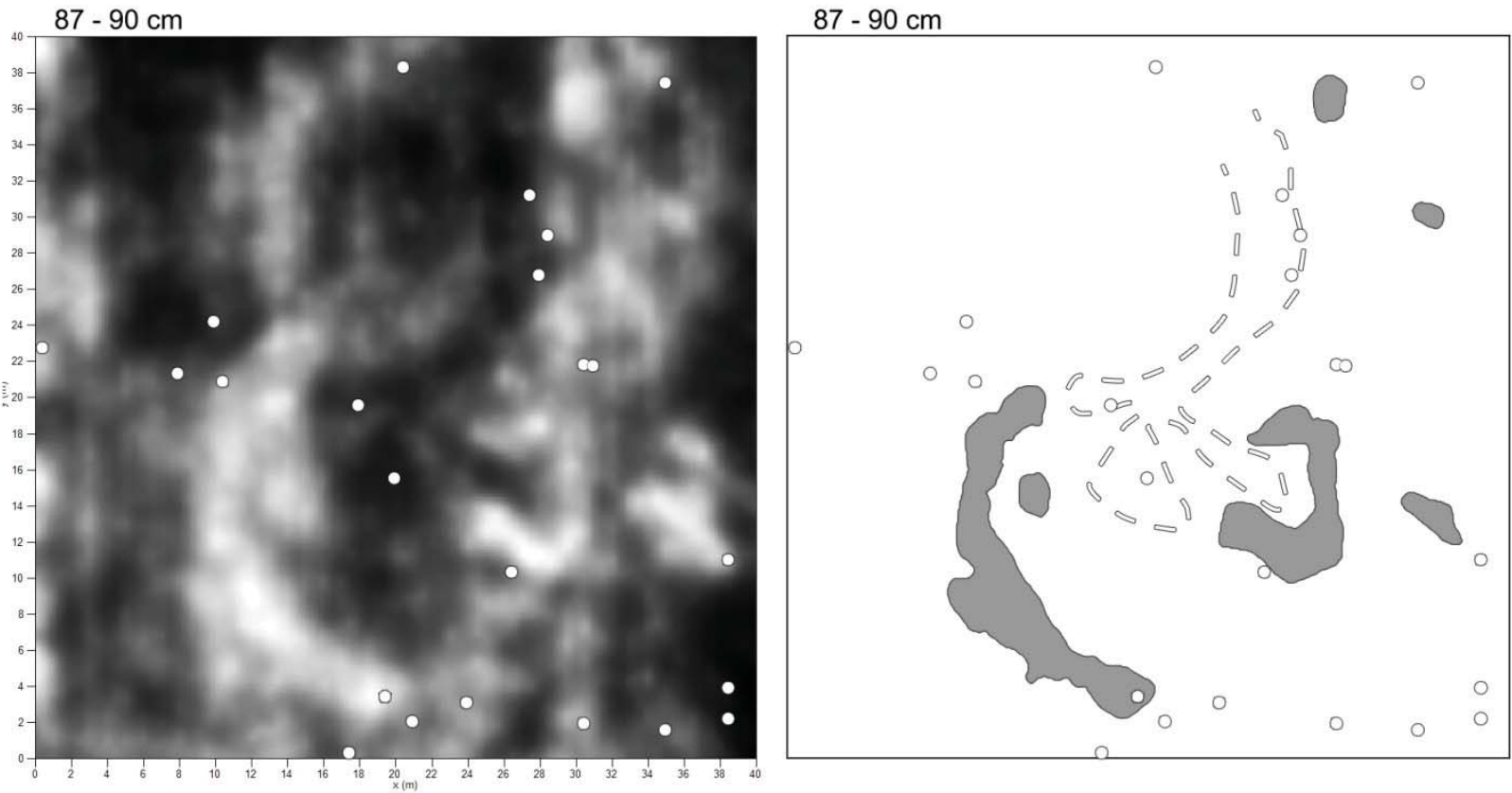

Figure 11. Multiple reflections plotted over the Mound D slice (left) and over the drawn features from Mound D (right).

floor, which in turn is roughly centered within the square structure suggesting that the post is a center post. Although walls are no longer evident in this layer, based on the positioning of the structure seen in the deeper layer, the two other post molds may be corner posts. Three MRs are grouped within the annex extending to the northwest of the prepared floor. These may be post molds associated with internal architecture.

It seems likely that the features present in the amplitude slices from Mound B represent charnel house architecture like that found at the Harlan site (Bell 1972). Harlan-style charnel houses have also been uncovered during excavations at the two other multi-mound civic-ceremonial centers in northwest Arkansas, the sites of Goforth-Saindon and Hunstsville (Kay et al. 1989; Kay and Sabo 2006). The Collins Mound B structure has a number of characteristics associated with Harlan-style charnel house architecture. The structure is perfectly square and has an extended entranceway opening to the southwest. A southwestern facing extended entranceway is keeping within a tradition identified by Kay and Sabo (2006: 44) in which "entryways oriented generally to the southwest, thus aligned with the winter solstice sunset" are pointing toward the direction symbolically associated with death.

\section{Mound C}

The GPR data from Mound C suggests that there are at least two, possibly three, different occupational layers containing structural elements present within the mound stratigraphy. The deepest context, as shown in the slice from 101-103 cm, exhibits what are interpreted as four post molds represented as four small circles of high amplitude organized in a " $U$ " shaped pattern. Each of the four circles corresponds with multiple reflections present in the profiles, further supporting the interpretation that they are post molds. Directly to the east of the post molds is an area of low amplitude resembling the shape of an " $\mathrm{X}$ ". There is not enough contextual information to identify this feature; however, it is possible that it represents an area of compacted soil. It is possible that it may be associated with a structure due to a series of MRs dotted along its perimeter.

Structural features become more evident when moving up to the middle context of the mound stratigraphy, as shown in the slices from $83-85 \mathrm{~cm}$ and $74-76 \mathrm{~cm}$. In the slice from $74-76 \mathrm{~cm}$, the shape of a structure measuring approximately $20 \times 35 \mathrm{~m}$ takes form. The structure appears to have openings, which may represent entrances, in the middle of its north and south faces. These openings lead to areas of high 


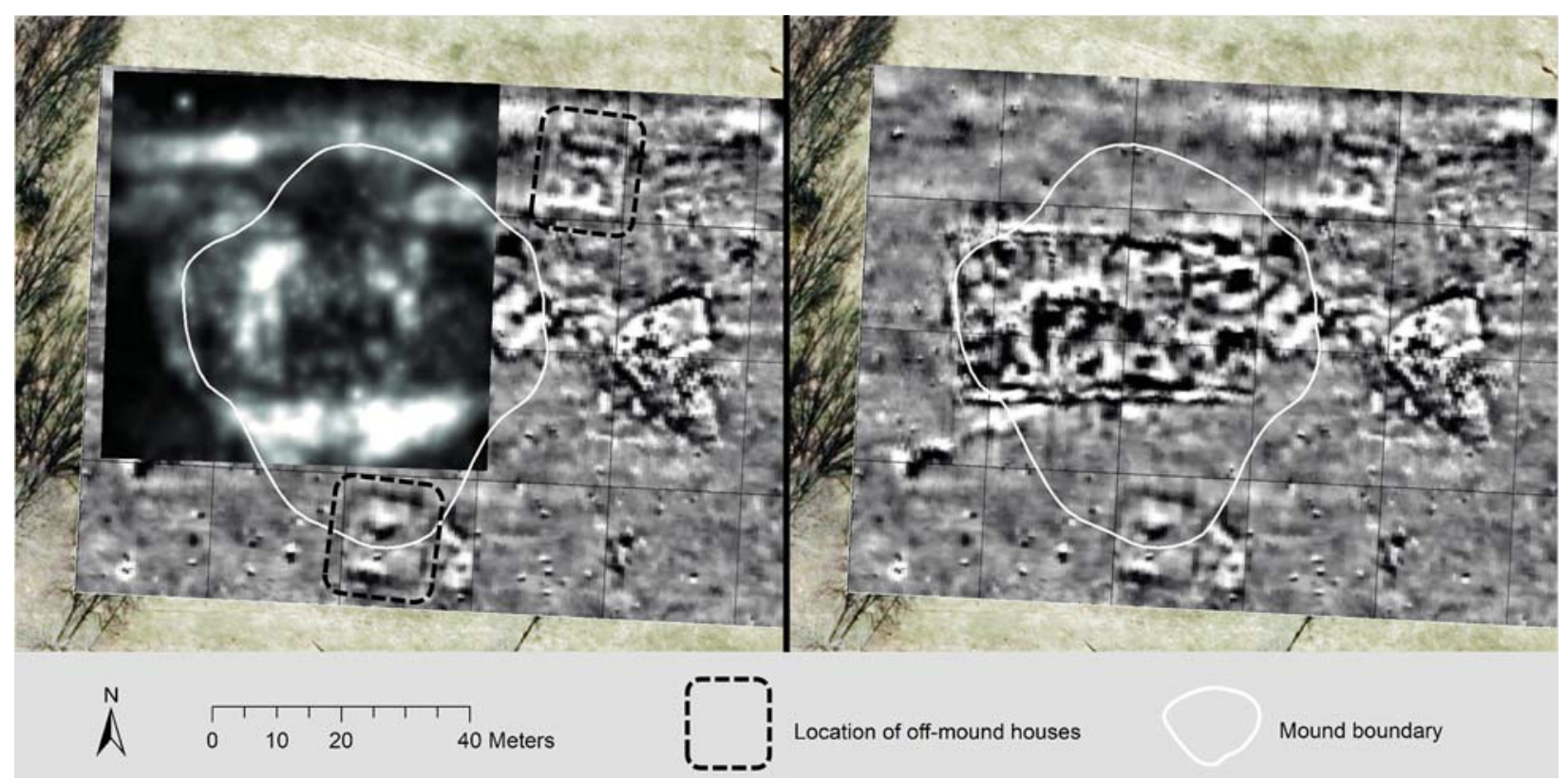

Figure 12. Side by side comparison of GPR and magnetic gradiometry data from Mound C. On the left, GPR data is draped over magnetic gradiometry data along with locations of off-mound houses mentioned in the text. Magnetic gradiometry data only in the imagery on the right.

amplitude within the structure, possibly representing internal architecture. Many of these areas of high amplitude continue in the same locations in the slices from $83-85 \mathrm{~cm}, 74-76 \mathrm{~cm}$, and $48-50 \mathrm{~cm}$.

The shallowest context of Mound C stratigraphy, as shown in the slice from $48-50 \mathrm{~cm}$, clearly exhibits a rectangular structure larger than the structure from the middle context, measuring approximately $23 \times 45 \mathrm{~m}$. This structure also appears to have entrances on both its northern and southern faces. The opening on the southern face corresponds to a feature in the magnetic gradiometry data that has been interpreted as an extended entryway (Sullivan and McKinnon 2013).

Regretfully, we are missing GPR data for the eastern boundary of Mound C, which might help in interpreting if there was an entryway on the east face of the structure. The magnetic gradiometry data from this mound (Sullivan and McKinnon 2013) shows an architectural feature exhibiting an unusual orientation on the easternmost part of the mound (see imagery on right side of Figure 12). In the magnetic gradiometry data, it appears that this unusual architectural feature is attached to the eastern face of the primary structure on the mound and that it may offer an entrance into the primary structure. Because magnetic gradiometry survey returns a two-dimensional view of variations in the magnetic field of the near-subsurface, it is difficult to determine the depth of the feature. And with the easternmost part of the primary structure missing from the GPR data, we are not able to determine if the smaller feature is indeed an unusual architectural feature associated with the primary structure or if it represents the remains of a square house concomitant with a different layer of occupation.

Also apparent in the magnetic gradiometry data are at least two small, square structures located adjacent to the mound (see Figure 12). Due to their low magnetic values, it does not seem that these smaller square structures were burned, and their sizes are appropriate to be houses. Each house is located near an entrance to the structure on the mound as seen in the GPR data. One possible interpretation is that the large structure associated with the shallow context of Mound C was used for a purpose that would require regular tending to by one or more officials who resided in the adjacent houses. Ethnohistoric accounts of the Hasinai Caddo by Spanish missionaries Fray Francisco Casañas de Jesús María and Fray Isidro Felis de Espinosa during the late seventeenth and early eighteenth centuries describe such a practice. At the temple of the xinesi, or the fire temple, a perpetual fire was maintained by the xinesi, or high 


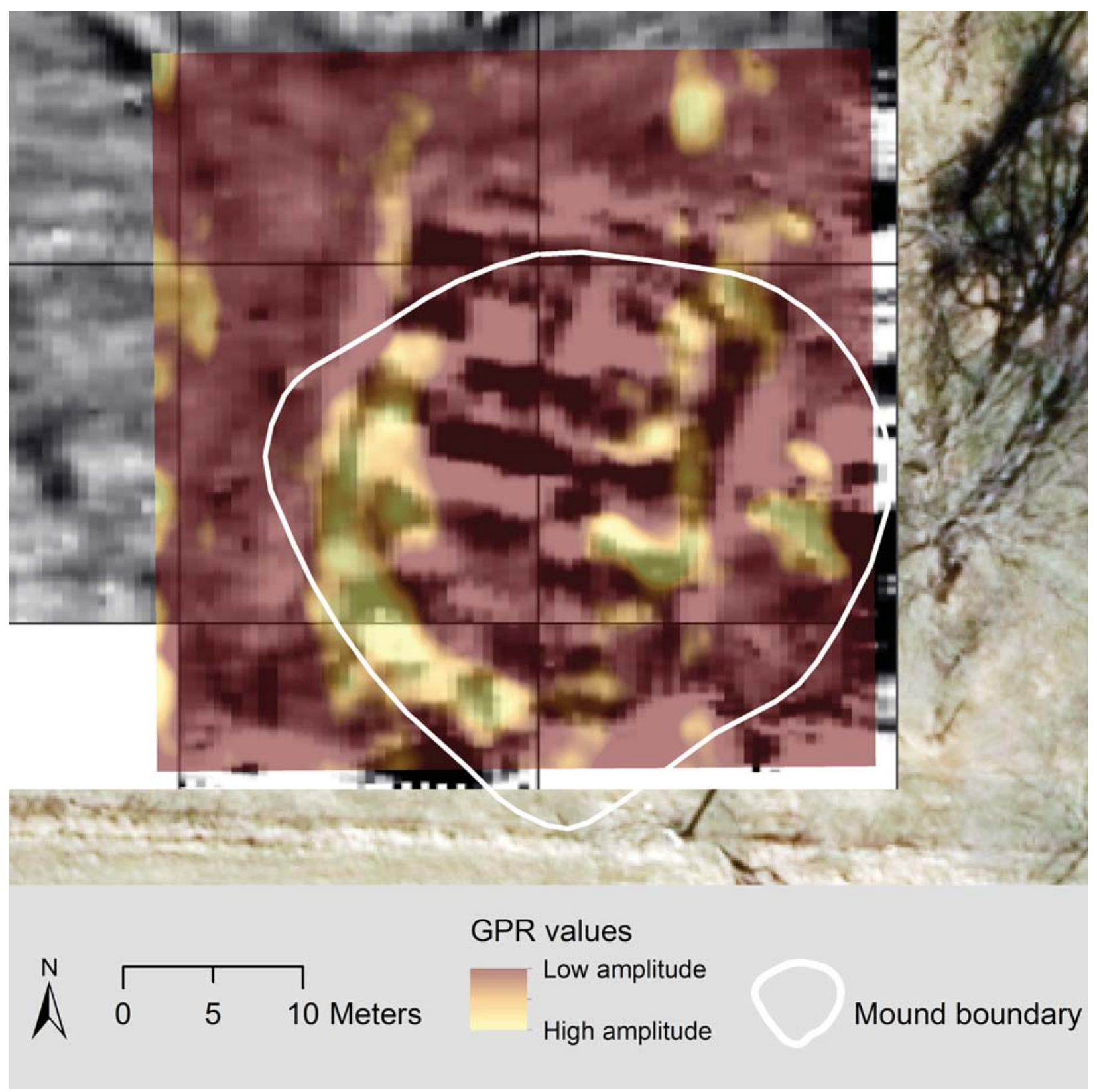

Figure 13. GPR data from Mound D displayed at 50 percent translucency and draped over the magnetic gradiometry data.

priest (Hatcher 1927). According to Casañas, the xinesi lived "about a hundred paces away" (Hatcher 1927:292) from the fire temple in a house which was much smaller than the fire temple (Hatcher 1927:290).

An additional interpretation regarding the architecture associated with Mound $\mathrm{C}$ is that it consists of a large enclosure containing an internal structure. This interpretation was first suggested by Sullivan and McKinnon (2013); and, although difficult to prove without excavation, it seems possible based on the recent GPR data. The potential for these structural elements to represent a charnel house is furthered as areas of high amplitude in the GPR slices from 83$85 \mathrm{~cm}, 74-76 \mathrm{~cm}$, and $48-50 \mathrm{~cm}$ continue in the same locations throughout the slices. Multiple sources from sites containing Harlan-style charnel houses report the same orientation for post molds and walls used in successive building episodes (Bell 1972; Kay at al. 1989; Kay and Sabo 2006). 
Finally, it should be noted that a historic road extending west to east across the northern part of the GPR survey is visible in the amplitude slice from $48-50 \mathrm{~cm}$. The road is also visible in the magnetic gradiometry data (Figure 12) although can no longer be seen from the ground surface.

\section{Mound D}

Mound D is the smallest of the three mounds in both diameter and height. Only one layer of the data, illustrated in the slice from $87-90 \mathrm{~cm}$, provided an interesting archaeological context (see Figure 10). The features most apparent in the amplitude slice appear to be circular in nature. However, when overlaying the amplitude slice onto the magnetic gradiometry data, the circular features actually correlate to the linear structural features in the magnetic gradiometry data (Figure 13).

Although it is not known what the " $\mathrm{X}$ " like feature of low amplitude may represent (see Figure 10), it is interesting to note that a comparable feature seen in the deepest context of Mound $\mathrm{C}$ is roughly the same size and exhibits a similar orientation. Similarly, both of these features have a series of MRs associated with their peripheries (see Figures 9 and 11). Other than making basic descriptions of the features present in the geophysical data from Mound D, it is difficult to provide further interpretations based on the data available.

\section{Conclusions}

The use of inquiry-based archaeogeophysical survey over the northern section of the Collins site has yielded information that would otherwise be unattainable given the restriction on excavation at the site. Groundpenetrating radar provides a complementary dataset to compare against previously acquired magnetic gradiometry data and reveals a number of new structural features over the mounds. A number of the structural attributes found in the architecture on Mound B are comparable with those found in Harlan-style charnel houses. The presence of a Harlan-style charnel house at the Collins site supports the idea of a shared ideology, traditions and ceremonialism among the contemporaneous peoples living in the western Ozark Highlands.
It is likely that multiple episodes of construction took place over Mound C. The structure most prominently visible in the geophysical data may represent a special use building tied to priestly activities. Its large size, which is larger than structures reported at other mound sites in the region, suggests communal or ceremonial use.

The geophysical data presented in this article highlights the potential wealth of information that the Collins site holds for understanding the nature of ceremonialism and social organization in the northern Caddo area.

\section{Acknowledgements}

This research was supported by the Arkansas Archeological Survey and the Center for Advanced Spatial Technologies at the University of Arkansas. Adam Weiwel and Autumn Cool collaborated with aerial imaging. Bill and Mary Shofner graciously provided access to the northern portion of the site. Special thanks are owed to the numerous volunteers who generously gave their time to assist with the surveys. Without them this research would not have been possible.

\section{References Cited}

Bell, Robert E.

1972 The Harlan Site, Ck-6, A Prehistoric Mound Center in Cherokee County, Eastern Oklahoma. Memoir 2. Oklahoma Anthropological Society, Norman.

Clay, R. Berle

2001 Complimentary Geophysical Survey Techniques: Why Two Ways are Always Better than One. Southeastern Archaeology 20(1):31-43.

Cool, Autumn Chrysantha

2015 Aerial Thermography in Archaeological Prospection: Applications \& Processing. Unpublished Master's thesis, Department of Anthropology, University of Arkansas, Fayetteville. 
Conyers, Lawrence B.

2013 Ground-Penetrating Radar for Archaeology. 2nd ed. AltaMira Press, Lanham.

Ernenwein, Eileen G. and Kenneth L. Kvamme

2008 Data Processing Issues in Large-area GPR Surveys: Correcting Trace Misalignments, Edge Discontinuities and Striping. Archaeological Prospection 15:133-149.

Gaffney, Chris

2008 Detecting trends in the prediction of the buried past: a review of geophysical techniques in archaeology. Archaeometry 50(2):313-336.

Goodman, Dean and Salvatore Piro

2013 GPR Remote Sensing in Archaeology. Springer, Verlag.

Harrington, Mark R.

1920 Certain Caddo Sites in Arkansas. Indian Notes and Monographs, Miscellaneous Series No. 10. Museum of the American Indian, Heye Foundation, New York.

Hatcher, Mary Austin

1927 Descriptions of the Tejas or Asinai Indians, 16911722. Southwestern Historical Quarterly 30-31.

Jol, Harry M.

2008 Ground Penetrating Radar Theory and Applications. Elsevier, Amsterdam.

Kay, Marvin and George Sabo, III

2006 Mortuary Ritual and Winter Solstice Imagery of the Harlan-style Charnel House. Southeastern Archaeology 25:29-47.

Kay, Marvin, George Sabo, III, and Ralph Merletti 1989 Late Prehistoric Settlement Patterning: A View from Three Caddoan Civic-ceremonial Centers in Northwest Arkansas. In Contributions to Spiro Archaeology: Mound Excavations and Regional Perspectives, edited by J. Daniels Rogers, Don G. Wyckoff, and Dennis A. Peterson, pp. 129-157. Studies in Oklahoma's Past No. 16. Oklahoma Archeological Survey, Norman.
Kvamme, Kenneth L.

2003 Geophysical surveys as landscape archaeology. American Antiquity 68(3):435-457.

2006 Integrating multidimensional geophysical data. Archaeological Prospection 13:57-72.

2007 Integrating multiple geophysical datasets. In Remote Sensing in Archaeology, edited by J. Wiseman and F. El-Baz, pp. 345-374. Springer, New York.

Neubauer, Wolfgang

2004 GIS in archaeology - the interface between prospection and excavation. Archaeological Prospection 11:159-166.

Perttula, Timothy K.

1992 “The Caddo Nation”: Archaeological and Ethnohistoric Perspectives. University of Texas Press, Austin.

2009 Extended Entranceway Structures in the Caddo Archaeological Area. Southeastern Archaeology 28(1):27-42.

Perttula, Timothy K. and Robert Rogers

2007 The Evolution of a Caddo Community in Northeastern Texas: The Oak Hill Village Site (41RK214), Rusk County, Texas. American Antiquity 72(1):71-94.

Rogers, J. Daniel

1982 Specialized Buildings in Northern Caddo Prehistory. In Southern Plains Archaeology, edited by Susan C. Vehik, pages 105-117. Papers in Anthropology 23(1). Department of Anthropology, University of Oklahoma, Norman.

Schultz, Thomas Clay

2010 Architectural Variability in the Caddo Area of East Texas. Unpublished Ph.D. dissertation, Department of Anthropology, University of Texas, Austin. 
Spock, Carolyn

1977 An Analysis of the Architectural and Related Features at the George C. Davis Site. Master's thesis, Department of Anthropology, University of Texas, Austin.

Sullivan, Stephanie M. and Duncan P. McKinnon

2013 The Collins Site (3WA1): Exploring Architectural Variation in the Western Ozark Highlands. Southeastern Archaeology 32:70-84.

Sullivan, Stephanie, Wojciech Ostrowski, and Kasper Hanus

2015 Low Altitude Prospection of early Mississippian mounds at the Collins site, Elkins, Arkansas. Contributions in New World Archaeology 8:125134.

Thompson Victor D. and Thomas J. Pluckhahn

2010 History, complex hunter-gatherers, and the mounds and monuments of Crystal River, Florida, USA: a geophysical perspective. Journal of Island and Coastal Archaeology 5:33-51.
Thompson, Victor D., Philip J. Arnold, III., Thomas J. Pluckhahn, and Amber M. Vanderwarker

2011 Situating Remote Sensing in Archaeology. Archaeological Prospection 18:195-213.

Trubitt, Mary Beth

2009 Burning and Burying Buildings: Exploring Variation in Caddo Architecture in Southwest Arkansas. Southeastern Archaeology 28(2):233247.

Walker, Chester P.

2009 Landscape Archaeogeophysics: A Study of Magnetometer Surveys from Etowah (9BW1), the George C. Davis Site (41CE19), and the Hill Farm Site (41BW169). Ph.D. Dissertation, Department of Anthropology, The University of Texas at Austin.

Webb, Clarence H.

1940 House Types among the Caddo Indians. Bulletin of the Texas Archeological and Paleontological Society 12:49-75. 